\title{
Mundos conflictivos en El trueno entre las hojas, una colección de cuentos integrados de Augusto Roa Bastos
}

\author{
An Van Hecke ${ }^{1}$
}

Resumen. En este artículo se hace un análisis de los temas y técnicas recurrentes en El trueno entre las hojas (1953), lo que lleva a considerar el libro como una colección de cuentos integrados con una unidad interna bien particular. Para empezar, la atención se centra en la influencia del surrealismo y en las ideas socio-políticas de Roa Bastos. Gran parte del artículo se dedica luego al análisis de algunos conceptos de la teoría psicoanalítica como los mitos, los arquetipos y los sueños. También se hace una comparación entre Roa Bastos y García Lorca. El último tema que se revela como una constante, es el bilingüismo español-guaraní. Los cuentos de El trueno entre las hojas revelan toda una serie de oposiciones, de mundos en conflicto: tradición y modernidad, mito y civilización, español y guaraní... Roa Bastos proporciona una visión universal del hombre a través de mitos que tienen su origen en un pasado remoto de la humanidad y que se reactualizan en el pueblo paraguayo.

Palabras clave: Augusto Roa Bastos; colección de textos integrados; surrealismo; mitos; bilingüismo.

\section{[en] Conflictive worlds in El trueno entre las hojas, a short story collection by Augusto Roa Bastos}

\begin{abstract}
In this article it is our purpose to analyse recurring patterns, both formal and thematic, in El trueno entre las hojas (1953), which leads us to consider the book as a short story collection with a strong internal unity and coherence. To begin with, the focus is on the influence of surrealism and the socio-political ideas of Roa Bastos. Much of the article is then devoted to the analysis of some concepts of psychoanalytic theory, in particular myths, archetypes and dreams. A comparison is also made between Roa Bastos and García Lorca. The last topic is bilingualism SpanishGuarani. The short stories of El trueno entre las hojas reveal several conflicts between different worlds: tradition and modernity, myths and civilization, Spanish and Guarani... Roa Bastos provides a universal vision of man through myths that have their origin in a remote past of humanity and that reappear in the Paraguayan people.
\end{abstract}

Keywords: Augusto Roa Bastos; short story collection; surrealism; myths; bilingualism.

Sumario: 1. Una colección de cuentos integrados: técnicas y temas recurrentes. 2. El surrealismo. 3. Compromiso político y lenguaje subversivo. 4. Mitos, arquetipos y sueños. 5. Roa Bastos y García Lorca. 6. El bilingüismo español-guaraní. 7. Conclusiones.

Cómo citar: Van Hecke, A. (2021) Mundos conflictivos en El trueno entre las hojas, una colección de cuentos integrados de Augusto Roa Bastos, en Anales de Literatua Hispanoamericana 50, 213-223.

\section{Una colección de cuentos integrados: técnicas y temas recurrentes}

En comparación con las novelas Hijo de hombre (1960) y Yo el Supremo (1974), parece que la crítica ha dedicado menos atención a El trueno entre las hojas (1953), un libro de relatos que pertenece a la primera etapa de Roa Bastos como escritor. ${ }^{2}$ De ahí que consideremos importante profundizar algo más esta colección de cuentos que se caracteriza por una gran sensibilidad hacia la naturaleza y que toca el ámbito de lo mágico. Hay varios elementos en El trueno entre las hojas que llevan a considerarlo como un auténtico

\footnotetext{
1 KU Leuven (Universidad de Lovaina). Bélgica.

E-mail: an.vanhecke@kuleuven.be

${ }^{2}$ En su libro de 1996, Brent J. Carbajal ya observaba lo mismo: "Esta colección a menudo es ignorada por la crítica de hoy en día, la cual prefiere estudiar las novelas posteriores de Roa" (Carbajal, 1996: 39). Esto puede explicarse en parte por el hecho de que este libro, uno de los primeros trabajos de Roa Bastos, contenga todavía "fallos estilísticos ocasionales" (Carbajal, 1996: 40).
} 
conjunto de cuentos enlazados o "textos integrados" (Brescia y Romano, 2006). James Nagel, en su libro The Contemporary American Short Story Cycle define la colección de cuentos integrados como sigue:

Indeed a central point is that in the short-story cycle each component work must stand alone (with a beginning, middle and end) yet be enriched in the context of the interrelated stories. [...] Although there have been myriad variations on the concept, the unifying tendency of the genre of the cycle has been the collection of a group of independent stories that contain continuing elements of character, setting, action, imagery, or theme that enrich each other in intertextual context. (Nagel, 2001: 15)

En las colecciones de cuentos integrados siempre hay una tensión entre unidad y diversidad, pero cabe distinguir entre la intención del autor y la lectura individual de cada lector. Según Robert Luscher, depende finalmente del lector si este reconoce estructuras y temáticas recurrentes (Luscher, 1989: 149).

Para empezar vemos la reaparición de algunos personajes a través de los cuentos. Se trata, en particular, del pueblo, personaje colectivo y "principal", pero también están los carpincheros del primer cuento titulado 'Carpincheros', sobre los que Rabassa señala acertadamente: "Cuando no son los protagonistas, aparecen en otros cuentos simbólicamente encarnando el espíritu de la vida errante y libre" (Rabassa, 1955: 151). Asimismo Gretchen, la niña alemana del mismo cuento, que huyó atraída por la vida aventurera de los carpincheros, vuelve a aparecer al final del libro en el cuento 'El trueno entre las hojas': es "la muchacha del río" $(233,249){ }^{3}$ La repetición de personajes tiene un objetivo bien particular según Aldana: "Podemos ver que Roa Bastos emplea la recurrencia de personajes y otros elementos en su obra para dar al lector la sensación de realidad y familiaridad con el mundo que ha creado" (Aldana, 1975: 180).

Los diferentes cuentos también se conectan por la manera en que se percibe el tiempo. Muchos cuentos de El trueno entre las hojas no siguen una línea cronológica. Los saltos en el tiempo pueden ser el resultado de una yuxtaposición de visiones o de una forma de escritura automática, como por ejemplo en 'Cigarrillos "Máuser", donde se presenta una sucesión de imágenes del delirio:

Ve a un chico tumbado junto a un árbol $[\ldots]$

Ve también al lado del chico a un perro, verdeoscuro [...]

Ve la lucha del perro con la víbora [...]

Ve al tiempo huir y al espacio achicarse $[\ldots](104-105)$

La discontinuidad temporal también puede explicarse por el uso continuo de flash-backs. En casi todos los cuentos los recuerdos se intercalan en el relato lineal. Lilí Olga Trevisán descifra estos juegos temporales en la novela Hijo de hombre y los considera como una especie de fuerza motriz de la acción novelística: "Avance, retroceso, acción fuera del tiempo, superposición y entrecruzamientos: todo esto hace que la acción palpite con notable fuerza" (Trevisán, 1967: 100). Esta interpretación también se aplica a El trueno entre las hojas.

También a nivel temático hay una conexión entre todos los cuentos. En este contexto resulta útil la observación de Nagel sobre colecciones de cuentos de y sobre ciertos grupos étnicos, un aspecto que el crítico ha estudiado en la literatura norteamericana:

One of the most fascinating aspects of the contemporary fictional cycle is that writers from a wide variety of ethnic groups have used the form for the depiction of the central conflicts of characters from their own race or nationality. As "American" narratives, these stories often involve the process of immigration, acculturation, language acquisition, assimilation, identity formation, and the complexities of formulating a sense of self that incorporates the old world and the new, the central traditions of the country of origin integrated into, or in conflict with, the values of the country of choice. (Nagel, 2001:15)

Estos son también los temas centrales en El trueno entre las hojas: la aculturación, el lenguaje, la asimilación, la formación de la identidad, el conflicto entre tradición y modernidad..., pero hay otros aspectos que conectan estos cuentos de Roa Bastos. Así por ejemplo, está siempre la naturaleza poderosa que pesa sobre los seres humanos, aunque al mismo tiempo se manifiesta en toda su belleza. Los ríos, como el río

\footnotetext{
${ }^{3}$ Augusto Roa Bastos (1977) El trueno entre las hojas. Barcelona: Editorial Bruguera. Citamos por esta edición. A partir de aquí se incorporarán al texto las páginas correspondientes entre paréntesis.
} 
Paraná, y los bosques guardan muchos secretos y misterios. Otro tema principal que atraviesa todos los cuentos es la justicia por lo que, en términos de Foster, estos primeros cuentos también caben dentro del "núcleo de todo su proyecto como escritor: esbozar la imagen del Paraguay y de su pueblo hostigado y perseguido y asentar los criterios que tienen que animar el compromiso del novelista ante este material" (Foster en Burgos, 1988: 37). Además de los personajes, los juegos temporales, los temas como la naturaleza y la justicia, hay otras constantes en el libro que examinamos ahora con más detalle.

\section{El surrealismo}

Fascinado por la magia y lo misterioso del mundo paraguayo, Roa Bastos ha construido una obra que varios críticos han calificado como surrealista, incluso "subrealista" o "superrealista". Para Rodríguez-Alcalá, el superrealismo en Roa Bastos "ya no es una moda sino una verdadera religión literaria" (1955: 25). De hecho, el surrealismo aparece a menudo como una entre muchas calificaciones de Roa Bastos, tal como lo hace Vila Barnés: "A Roa se le ha calificado de escritor realista -matizando su personalísima visión con los calificativos más variados: tremendista, surrealista, populista, mágicorrealista. Creemos que él es todo esto sellándolo con su propia personalidad" (Vila Barnés, 1984: 27). Riccardo Castellani, en su artículo "Surrealismo en el Paraguay", descubre la influencia del surrealismo sobre todo en la poesía de Roa Bastos:

Así como los surrealistas tendieron hacia otros misticismos alternativos al del catolicismo imperante [...] la poesía paraguaya busca su fundamento en la tradición de los primeros habitantes de estas tierras. El segundo libro de poesía de Roa Bastos incluirá una versión poética en castellano de la leyenda de la creación y juicio final del mundo de los apopokuva-guaraní. (Castellani, 2012: 135)

Asimismo, Patricia Montenegro, en un estudio sobre Hijo de hombre, parte de los Manifiestos de André Breton para analizar "la creación de imágenes arbitrarias y surrealistas" en el autor paraguayo (Montenegro, 2015: 188, mi traducción).

Cabe agregar que Roa Bastos escribió un libro titulado Los 1000 y un proverbios rebeldes que lamentablemente desapareció (como otros textos de Roa Bastos, debido probablemente a sus exilios). El periodista español Antonio Carmona, amigo de Roa Bastos, dijo al respecto: "Eran aforismos que nunca se encontraron y de tono surrealista. A él le gustaba mucho el cine de Luis Buñel" (Carmona citado en Orozco, 2015).

Los escritores y artistas cuyas obras se sitúan dentro del surrealismo europeo se dedicaban a múltiples temas como el amor sublime y el erotismo, los ritos y los juegos, el encuentro con la locura, los mitos, los sueños o las especulaciones esotéricas (Berranger, 1997). También se quedaban fascinados por objetos como el espejo, conceptos como la inocencia, la muerte y la noche (Rispail, 1991). Una de las técnicas surrealistas más conocidas sin duda es la de la escritura automática que consiste en "redactar un texto dictado por una necesidad interna, el subconsciente por ejemplo, sobre el cual no podemos ejercer ningún poder" (Lewi, 1989: 43, mi traducción). Breton formula la receta de este arte mágico surrealista como sigue:

On vide son esprit,

On laisse jaillir les mots spontanément,

On laisse parler le langage, s'opérer une sorte de dictée de l'inconscient,

On transcrit strictement ce qui apparaît dans la conscience claire.

(Breton citado en Lewi, 1989: 43)

No se puede subestimar el impacto que ha tenido el surrealismo francés en muchos autores y artistas a lo largo del siglo veinte, también en América Latina. En la pintura cabe mencionar la obra de Leonora Carrington, artista de origen inglés quien se estableció en México en los años cuarenta y se inspiró en los mitos aztecas para crear a "sus héroes que son mitad bestias mitad hombres" (Rispail, 1991: 124, mi traducción). Pero también han sido fundamentales las obras de Wifredo Lam, Frida Kahlo o Remedios Varo. Entre los poetas es imprescindible mencionar a Octavio Paz, quien se unió al movimiento surrealista en 1950 (Rispail, 1991: 125). Su amistad con los surrealistas franceses lo llevó a experimentar con la escritura automática. Paz subraya en una entrevista con Mac Adam la importancia del surrealismo francés: "Los surrealistas incorporaron algo que los franceses habían olvidado: el otro lado de la razón, el amor, la libertad, la poesía" (Paz en Mac Adam, 1991, mi traducción). En su artículo "El surrealismo y la literatura iberoamericana" - un texto algo polémico-, Cedomil Goic opina con razón que "el concepto de una América de maravillas reales superiores a las fantasías renacentistas [...] ni lo maravilloso del mundonovismo 
requirieron para nada del surrealismo. Pero no cabe duda igualmente, que el surrealismo se convierte en instrumento adecuado para el descubrimiento de lo real maravilloso americano [...]" (Goic, 1977: 29). Fernando Buen Abad Domínguez, a su vez, hace un recorrido de la influencia del surrealismo en los autores latinoamericanos y señala algo bien cierto sobre el movimiento de ida y vuelta entre Europa y América Latina:

Pero también el Surrealismo que vino, volvió a Europa cargado con voces latinoamericanas... un ir y venir que tiene en su historia capítulos fundamentales para comprender el presente del pensamiento Latinoamericano en muchas de sus áreas fundamentales. Es el caso de Julio Cortázar, Octavio Paz, Alejo Carpentier... desde México hasta Argentina el humor rebelde de los surrealistas trabaja sobre los hechos absurdos de la vida, de la política, de la cultura burguesa. Y la influencia del surrealismo no se detuvo ahí, abrió un método transformador que contribuyó al fulgor de autores como Pablo Neruda, Wilfredo Lam... Vicente Huidobro, Angel Cruchaga, Rosamel del Valle, Braulio Arenas [...]. (Buen Abad Domínguez, 2007: s.p.)

Así como Patricia Montenegro lo ha analizado en el caso de Hijo de hombre, tomamos el surrealismo como punto de partida para investigar otros aspectos en El trueno entre las hojas. A continuación nos centramos en la realidad socio-económica y el compromiso político de Roa Bastos. Luego analizaremos los cuentos de El trueno a partir de unos conceptos psicoanalíticos como el mito, el arquetipo y el sueño. Verificaremos también lo que Roa Bastos pueda tener en común con García Lorca. Finalmente analizamos el bilingüismo en los cuentos.

\section{Compromiso político y lenguaje subversivo}

En los estudios sobre Roa Bastos domina un enfoque principalmente sociológico, en el que se relaciona su obra con la historia de Paraguay. ${ }^{4}$ Esto no tiene nada de sorprendente ya que tanto sus novelas como sus cuentos se caracterizan por un gran compromiso social. El trueno entre las hojas lo escribió además desde su exilio político en Argentina. Roa Bastos siempre ha manifestado una preocupación por la sociedad paraguaya, cuyo pueblo ha sido víctima de la opresión política, la pobreza, las guerras y el aislamiento a lo largo de casi todo el siglo veinte. Podemos calificar la obra de Roa Bastos como literatura comprometida, pero también acierta Bareiro Saguier cuando opina que Roa Bastos no hace "literatura de tesis", no adopta "fórmulas baratas" ni cae en una forma de "maniqueísmo" (Bareiro Saguier, 1976: 40). Esto se debe probablemente al hecho de que Roa Bastos se mueva entre lo local y lo universal como bien esclarece Díaz Ruiz: "Este narrador hace una literatura referida eminentemente a cuestiones paraguayas; se inscribe dentro del ciclo de la novela telúrica y regional, al tiempo que participa en el movimiento narrativo que logra la plena universalización de la literatura de América Latina." (Díaz Ruiz, 1991: 38).

Aunque la literatura de Roa Bastos no alcance los extremos del surrealismo francés, en muchos de sus cuentos el tono escandaloso está presente, como por ejemplo en la descripción de la posadera del cuento 'El Karuguá' cuyo relato es "confuso y entremezclado de su propio encono y perversidad" (136). También hay referencias a lo escatológico en el cuento 'La Rogativa'. Al lado de la imagen mitológica del tigre que orina, Roa Bastos esboza de una manera realista e incluso naturalista las mujeres que "mean sobre el polvo" (180). Rodríguez-Alcalá deplora aquí la tendencia al efectismo y lo considera como un "naturalismo obsceno", excesivo y "de mal gusto". Además, el crítico opina que "lo accesorio, lo adjetivo -y lo antiestético-, tienen un espacio y énfasis, en consideración a los cuales se sacrifica lo sustancial" (Rodríguez-Alcalá, 1955: 34, 38). Es posible que el lenguaje escandaloso y subversivo chocara a los lectores y los críticos de los años cincuenta, de la misma manera que los surrealistas franceses ofendieron al lector burgués de principios de siglo, pero es precisamente el efecto que Roa Bastos pretendía lograr en el lector. En este inconformismo con respecto a la tradición vemos a Roa Bastos como un escritor que destruye con el fin de poder construir algo nuevo. Sus cuentos respiran un tono de gran esperanza en el futuro y de fe en la bondad del hombre. Su estilo se vuelve más violento a medida que va creciendo su protesta contra la explotación del pueblo paraguayo y

\footnotetext{
${ }^{4}$ Véanse por ejemplo David William Foster (The Myth of Paraguay in the Fiction of A. Roa Bastos, 1969) o Brent J. Carbajal (Historia ficticia y ficción histórica: Paraguay en la obra de Augusto Roa Bastos, 1996).
} 
la corrupción de la clase rica. Dado su profundo sentimiento de justicia, Roa Bastos no puede sino comprometerse con su pueblo y defenderlo.

\section{Mitos, arquetipos y sueños}

Para este análisis resultan muy útiles algunos conceptos de la teoría psicoanalítica de Jung. Roa Bastos no va en busca de una inconsciencia paralela a la consciencia de cada individuo, tal como investigó Freud, sino que exhuma una "inconsciencia colectiva". Con este concepto Jung se refirió a la actividad dinámica creadora de mitos y símbolos que "se repiten en toda la tierra bajo formas idénticas" (Jung 1984: 69). Los personajes de los cuentos de El trueno entre las hojas no disponen de retratos psicológicos complejos, por lo que no parecen actuar como individuos sino que son más bien representantes de un solo protagonista: el pueblo. Este personaje colectivo es el mismo en todos los cuentos del libro.

Para empezar, el epígrafe del libro El trueno entre las hojas es una leyenda aborigen que alude a un significado mítico del fenómeno natural del trueno: "El trueno cae y se queda entre las hojas. Los animales comen las hojas y se ponen violentos. Los hombres comen los animales y se ponen violentos. La tierra se come a los hombres y empieza a rugir como el trueno" (23). La violencia en el mundo se multiplica y se vuelve circular. La circularidad asociada a cierto fatalismo es propia de los mitos. El hombre en esta leyenda no aparece como actor excepcional en la naturaleza, sino que a su vez es víctima de las fuerzas naturales. En 'La Rogativa', por ejemplo, la sequía lleva implacablemente al pueblo de Santa Clara al sufrimiento y a la desesperación. Si la niña Poilú come la tierra para matar el hambre, en realidad es la tierra la que devora a la niña: muere como víctima de la sequía y como sacrificio para obtener lluvia. Se alude aquí a una interpretación de la vida del hombre sometido a las fuerzas arbitrarias de la tierra devoradora, o del hombre mortal que regresa al lugar de origen, a la tierra-madre que le dio la vida. Otro cuento que constituye una prueba de este sometimiento del hombre a la naturaleza es 'Carpincheros', el primer cuento de la colección. El "lobo-pe", llamado también el "tigre del agua", ataca a un carpinchero (35). Al final, Gretchen, hija de una familia alemana que llegó a Paraguay poco después de la primera guerra mundial, desaparece con los carpincheros. De hecho Gretchen huye con los carpincheros atraída por su sentido de libertad y cae en manos de un poder cósmico representado por el trueno. Al grito de Ilse, "Gretchen, Gretchen" solo sigue "un trueno sordo" (39). ${ }^{6}$

Según Jung, la mitología se conforma de arquetipos que no son "imágenes mitológicas determinadas" sino "tendencias a formar tales representaciones" (Jung, 1984, 66). Uno de los arquetipos más llamativos sin duda es el héroe, y Roa Bastos construye muchos de sus cuentos alrededor de este personaje. El viejo señor obispo por ejemplo, del cuento del mismo título, es la reencarnación de la bondad, la justicia y la generosidad (40-56). Asimismo, Solano Rojas, del cuento 'El trueno entre las hojas', el último de la colección, se convierte en el gran héroe del pueblo (218-250). Es mitificado ya durante su vida, y después de su muerte sobrevive en la memoria del pueblo gracias a la música de acordeón que todos siguen oyendo (250). En su análisis sobre los relatos, Vila Barnés parte de la oposición "opresor versus oprimido" e interpreta al "héroe salvador" como la síntesis de estas fuerzas en oposición (Vila Barnés, 1984: 45).

Frente a la figura mitológica del héroe encontramos también la del antihéroe. En 'Mano Cruel', un cuento con tono irónico, los dos protagonistas pueden ser interpretados como tal: tanto el personaje Mano Cruel, demoniaco, corrupto y explotador, como el socio Críspulo Gauto, el hombre ingenuo y explotado (66-78). Asimismo, Liberato Farías, del cuento 'La gran solución', aparece como un antihéroe por su carácter individualista y cobarde. En el caso de Liberato, se percibe claramente una universalización del personaje corrupto (182-193).

Además del héroe y del antihéroe, aparecen otras figuras mitológicas en el mundo ficcional de Roa Bastos, a saber, los monstruos o seres deformados, como el enano giboso con signos de lepra, que roba a los

\footnotetext{
${ }^{5}$ Según Gladys Vila Barnés, estas palabras "le dan énfasis a dos elementos presentes en casi todos los cuentos de la colección: la violencia y la interrelación entre la naturaleza y el hombre. Ambos elementos aluden a la imagen del mundo presentada por el cuentista. Roa Bastos cree en la armonía existente entre el hombre y la naturaleza y entre el hombre y su semejante. En estos cuentos se considera el desmembramiento de esta unidad la causa engendradora del mal que ha aquejado siempre a su país: la violencia." (Vila Barnés, 1984: 27).

${ }^{6}$ Brent J. Carbajal ve en este cuento una clara influencia del Romanticismo del siglo diecinueve: "Un tema o preocupación importante del Romanticismo fue la exaltación de lo exótico, la huida de lo ordinario. La búsqueda y la atracción hacia lo exótico en 'Los Carpincheros' es de extraordinaria importancia, ya que Gretchen, la 'exótica' o 'forastera' en Paraguay se siente atraída por el exotismo de la población indígena paraguaya." (Carbajal, 1996: 50).
} 
niños en 'La tumba viva' (211). La memoria colectiva asocia el enano a figuras terribles de la mitología como el Luisón, el Pombero, el Pyta-Yovai, el Mboi yagua o el Yasi-Yatere, que según el glosario al final es "un personaje mitológico, representado por un enano rubio que aparece entre los maizales" (252). También los carpincheros arriba mencionados son seres mágicos y rituales que, según la protagonista Gretchen, vienen de la luna, un lugar maravilloso y fantástico en la imaginación de la niña. Estos "hombres de la luna" (28) pertenecen a un mundo primitivo que conserva una sabiduría desde tiempos inmemoriales y que se opone al llamado mundo civilizado de los alemanes.

En el mundo de los mitos, Jung les atribuye un papel particular a los niños: "la producción de arquetipos por los niños es especialmente significativa porque, a veces, se puede estar completamente seguro de que un niño no ha tenido acceso directo a la tradición respectiva" (Jung, 1984: 69). En Roa Bastos los niños ocupan un lugar especial en los mitos y las leyendas. ${ }^{7}$ Así por ejemplo, Gretchen, en 'Carpincheros' posee una sensibilidad extraordinaria para comprender el mundo fantástico de los carpincheros. Es como si la infancia de la niña correspondiera a la infancia de la historia. Hasta cierto punto, es Gretchen la que crea el mito, el secreto: "Los ríos bajan de la luna -se decía-. Si los ríos son sus caminos - concluía con lógica fantástica-, es seguro que ellos son los Hombres de la Luna." (28). Curiosamente, la niña misma aparece como un ser lunático, de otro universo: "De tan finos y rubios, sus cabellos parecían de leche, de azúcar, al resplandor de las fogatas. En esa cabecita lunada, el misterio de los carpincheros se revolvía en todas direcciones" (27).

También está la adolescente Isabel Miscowsky del cuento 'El Karuguá' (134-151). El mundo de Isabel siempre ha sido el lugar misterioso de Karuguá, un estero alejado del pueblo. Nadie la ha visto en estos quince años desde que nació y ella nunca ha ido al pueblo. Sin embargo, forma parte de la imaginación colectiva, y en particular de la imaginación de la posadera, sobre la que el narrador dice: "en la lengua de esta mujer se hallaba registrada un poco fonográficamente la conciencia del poblacho" (137). Hasta el propio narrador se crea una imagen de la muchacha: "Su rostro enigmático y hermoso como el de la madre flotaba a mi encuentro como una inminente revelación" (138). Isabel se ha convertido en una figura entre la realidad y la imaginación, entre la vida y la muerte: "La imaginé envuelta en los vapores nauseabundos como una criatura espectral y cayéndose también ella una noche en esta tumba sin fondo." (150). Paralelamente, en 'La rogativa' tenemos a Poilú, otro ejemplo de una niña con una capacidad sobrenatural de comunicarse con seres puros e incontaminados como Felipe Tavy, que según los adultos es solo un "viejo loco" (173). La infancia y la locura se juntan en la comprensión de los símbolos naturales: el gran pájaro (la sequía), el tigre azul que orina (la lluvia) y la aparición de la flor yasy-mörötï cuando llueve (173-174). El mundo mitológico de la niña Poilú contrasta con el mundo cristiano en el que creció. Un último personaje de la infancia, muy cercano al mundo ancestral de los mitos, es la pequeña Alicia del cuento 'La tumba viva' (203-217). Su muerte es representada como un sacrificio, por lo que Alicia entra en un ciclo natural, en el que el mal es considerado como un elemento necesario.

Uno de los conceptos claves del psicoanálisis, tanto en la obra de Freud como de Jung, es el sueño, que se percibe como uno de los medios más importantes para tener acceso a lo inconsciente colectivo. Sobre el mundo onírico, Jung dice lo siguiente:

Con frecuencia, en el sueño se producen elementos que no son individuales y que no pueden derivarse de la experiencia personal del soñante. Esos elementos, como ya dije antes, son lo que Freud llamaba "remanentes arcaicos", formas mentales cuya presencia no puede explicarse con nada de la propia vida del individuo y que parecen ser formas aborígenes, innatas y heredadas por la mente humana. (Jung, 1984: 65)

En los sueños que se relatan en los cuentos de Roa Bastos suele haber siempre una mezcla del pasado con el futuro. Además, se manifiesta a veces una confusión entre lo que es recuerdo y lo que es sueño propiamente dicho. En el cuento 'La excavación', Perucho Rodi está excavando un túnel para escapar de la prisión y así le surge el recuerdo de otro túnel, el de la Guerra del Chaco, que le aparece como un sueño lejano: "Soñó (recordó) que volvía a salir por aquel cráter en erupción hacia la noche azulada, metálica, fragorosa" (94). Se repite hasta tres veces esta misma estructura, "Soñó (recordó)", en la que los verbos soñar y recordar terminan confundiéndose. El fragmento culmina en un sueño circular al estilo borgiano: "Soñó que soñaba

\footnotetext{
${ }^{7}$ La iniciación de niños y adolescentes en el mundo de los adultos también ha sido interpretada como un arquetipo, algo que Aponte analiza en el cuento "Cigarrillos "Máuser" (96-105), sobre un niño inseguro y solitario que se siente psicológicamente alejado de su familia. En el rito de la iniciación, los niños a menudo vacilan entre la inocencia y el mal (Aponte, 1982: 50-51).
} 
en el túnel" (94). Otro cuento en el que los recuerdos se mezclan totalmente con los sueños es "Cigarrillos "Máuser". Un hombre que habla en el presente, de repente "ve" en el pasado: ve a un chico y un perro; ve la lucha del perro con la víbora y el cadáver de una negra: "Lo entrevé todo a través de la fiebre, de los gritos, del sueño" (105). Este motivo del sueño-recuerdo también es un elemento constitutivo del relato "El prisionero' en el que el soldado Hugo Saldívar lucha en balde contra el sueño, aunque tiene que estar de guardia y vigilar a un prisionero:

El sueño iba anestesiando gradualmente su voluntad. Trató de pensar en algo definido y concreto, pero sus recuerdos se mezclaban en un tropel lento y membranoso que planeaba en su cabeza con un peso muerto, desdibujado e ingrávido. En uno o dos destellos de lucidez, Saldívar pensó en su madre, en su hermano. (198199)

El sueño de Hugo le pone en contacto con el mundo feliz de su hermano, Víctor. Es un sueño lleno de esperanza de poder cambiar el mundo, de traer la vida a este rancho de muerte. Trágicamente, el recuerdo enseguida establece un nexo con el presente y el futuro: es un presagio de la muerte de Víctor. La fuerza del sueño consiste en poder recuperar recuerdos olvidados, a nivel individual, pero también puede haber sueños capaces de evocar los recuerdos más antiguos de la humanidad. Aquí es donde el sueño se relaciona con el concepto de lo inconsciente colectivo. Esto se ilustra en el cuento 'El prisionero'. Aquí el narrador omnisciente sitúa las causas primordiales de la crueldad de la guerra en el movimiento cíclico de la naturaleza, a saber, en el sueño de los dioses: "Las carnívoras divinidades aborígenes habían vuelto a mostrar entre el follaje sus ojos incendiados; los hombres se reflejaban en ellos como sombras de un viejo sueño elemental" (194). Aquí se evidencia cómo el viejo sueño de los dioses contenía al mismo tiempo una profecía: el terror de la guerra de los hombres ya estaba previsto en el sueño de los dioses. Esta misma fuerza extraterrestre del augurio la posee también la gitana en 'El ojo de la muerte', cuando le profetiza a Timó Aldama el momento de su muerte (60-61).

Según Jung la creación de los mitos tiene su origen en el sufrimiento del hombre: "Los mitos de naturaleza religiosa pueden interpretarse como una especie de terapia mental de los sufrimientos y angustias de la humanidad en general: el hambre, la guerra, la enfermedad, la vejez, la muerte" (Jung, 1984: 76). Los cinco elementos mencionados por Jung como las causas principales del sufrimiento humano son también los grandes males de la vida en Paraguay tal como Roa Bastos los presenta en su obra. La relación de causa y efecto entre el sufrimiento y el mito tiene una lógica: el hombre es capaz de crear en los mitos un mundo fantástico, feliz e irreal, gracias a su gran poder imaginativo. Roa Bastos quiere captar el mundo que lo rodea y lo hace a través de oposiciones. El mundo mitológico, de los arquetipos y los niños, un mundo primitivo, original y puro, se opone al mundo "civilizado" en el que reinan la corrupción, la explotación, la guerra y la pobreza. ${ }^{8}$

En este mundo irreal, que a los niños les aparece como la realidad, rigen las leyes de una lógica diferente. Considerando este mundo de los mitos y los sueños en su totalidad, podemos deducir que Roa Bastos se acerca también al realismo mágico. Esta corriente estilística encontró en América Latina un espacio apropiado para desarrollarse entre otras razones porque muchas leyendas e imágenes mitológicas aún no han desaparecido de la "inconsciencia colectiva".

\section{Roa Bastos y García Lorca}

En el "Perfil biográfico" de Roa Bastos, Antonio V. Pecci apunta que, a partir de los años cuarenta, Roa "[1]ee a Neruda, García Lorca, Alberti, Juan Ramón Jiménez, así como a Faulkner, Freud, Marx y otros autores". 9 (Pecci s.f.) No por haber leído a estos autores se puede hablar siempre de influencias, pero en el

\footnotetext{
${ }^{8}$ Carlos Pacheco percibe en los cuentos de Roa Bastos tantas binariedades opuestas que las considera como "modelo de concepción estética" del autor: "La presencia de estructuras binarias, de bipolaridades que se oponen, interactúan, se invierten y en algunos casos se identifican, es tan frecuente en los cuentos de Roa que puede pensarse como uno de los principios más claros de su concepción estética. Parece tratarse en efecto, de una suerte de modelo de pensamiento artístico que influye tanto en la organización general de los relatos como en la selección y elaboración de sus elementos temáticos y hasta en el más minucioso trabajo sobre el lenguaje." (Pacheco en Burgos, 1988: 156).

${ }^{9}$ No hemos podido encontrar comentarios explícitos de Roa Bastos sobre Lorca en entrevistas o ensayos, pero a partir de este dato biográfico apuntado por Pecci (s.f.), y sobre todo a partir de los estudios de Rodríguez-Alcalá (1955) y Tovar Blanco (2002) nos parece justificado explorar más esta pista de la influencia del poeta español en Roa Bastos.
} 
caso de García Lorca resulta interesante comparar la obra de ambos. Nos basamos sobre todo en los estudios de Rodríguez-Alcalá (1955) y Tovar Blanco (2002) quienes han estudiado la influencia de Lorca en Roa Bastos. Según Rodríguez-Alcalá, Roa Bastos era un gran admirador de la lírica de Lorca. El crítico analiza en detalle "el influjo del romancero lorquiano" en Roa Bastos y plantea que "García Lorca le abre a Roa Bastos la puerta de la nueva literatura". Rodríguez-Alcalá explica este impacto de Lorca en Roa Bastos:

Una vez dueño de todo el arsenal poético de Lorca; de toda esa imaginería onírica y alucinante, de todos los nuevos recursos retóricos, tales como le fueron accesibles en los volúmenes de las obras lorquianas publicados en aquel tiempo por la editorial Losada de Buenos Aires, Roa Bastos renuncia para siempre a sus predilecciones clásicas y se consagra a leer y a imitar con entusiasmo a todos los poetas nuevos. (RodríguezAlcalá, 1955: 23)

También Tovar Blanco, en su artículo "Ecos lorquianos en la memoria poética del Paraguay" percibe una influencia lorquiana en el autor paraguayo: "Se trata de liberar la historia creándola con palabras; intuyéndola, no pensándola esa nueva poesía que, entre otros, cita en su favor a Neruda, Alberti y, cómo no, a Lorca, todos comprometidos en un hecho literario, tan primitivo como el dolor de hoy, verbo de mañana." (Tovar Blanco, 2002: 98).

Existen diferentes elementos de influencia o analogía entre García Lorca y el escritor paraguayo (Tovar Blanco, 2002), pero enfocamos aquí dos aspectos: la afinidad espiritual de ambos con el surrealismo, y el uso particular de imágenes y metáforas. La influencia del surrealismo en Lorca ha sido objeto de algunas polémicas. Gracias a sus contactos con Luis Buñuel y Salvador Dalí, conoció a los surrealistas franceses que le influenciaron en su obra poética (Rispail, 1991: 96). Sin embargo, fue solo un periodo corto de su juventud en el que se lanzó a las experimentaciones surrealistas, tal como se refleja en El Público, obra de teatro inacabada (García Lorca, 1987). El público es una de las piezas más escandalosas escritas en España a principios del siglo veinte: lenguaje vulgar, yuxtaposiciones ilógicas, asociaciones inesperadas, confusión total entre el público ficticio y el real. No es evidente hacer una representación teatral del texto, aunque ya se han realizado algunas. Las características mencionadas en el caso de Lorca -el énfasis en lo escandaloso, el rechazo de toda lógica etc.- son elementos que encontramos también en El trueno entre las hojas, como analizamos arriba.

Sin embargo, Lorca abandona rápidamente esta tendencia surrealista para lanzarse a una poesía mucho más tradicional en cuanto a la forma, con la cual obtendrá un enorme reconocimiento en el mundo literario. Es el Lorca de los romances, de las imágenes frágiles, de la musicalidad, de las metáforas de la naturaleza, de lo mágico. Esta poética de la imagen también puede explicarse a partir del "renovado lírico" del surrealismo (Berranger, 1997: 125). Aquí nos encontramos con otro paralelismo entre Roa Bastos y Lorca. En su poesía, Roa Bastos se revela como gran creador de imágenes sutiles, pero también en sus cuentos está siempre presente la voz del poeta. Pensamos por ejemplo en la gitana que profetiza el futuro de Timó Aldama en 'El ojo de la muerte' (60). La mujer con los ojos verdes y el don sobrenatural del augurio evoca a los personajes del Romancero Gitano de Lorca: son todos seres de un mundo irreal, dominado por fuerzas mágicas. También Gretchen, la niña que desaparece con los Hombres de la Luna, nos hace pensar en el niño del primer romance del Romancero Gitano, 'Luna', donde la luna-madre engaña con su poderosa atracción y se lleva al niño gitano. A la dulce conversación entre el niño y la luna, sigue la muerte dolorosa del niño (García Lorca, 1986: 49-50). El símbolo de la luna, una de las imágenes preferidas de Lorca, es un verdadero leitmotiv en El trueno entre las hojas: lo vemos en 'Carpincheros', 'La rogativa' o 'El prisionero'. Aún más, los carpincheros en sus barcos son comparables a los gitanos en sus caballos: ambos grupos se asocian a visiones mitológicas y fantásticas.

Considerando estos cuatro personajes - la gitana, el niño muerto, la luna y los hombres mágicos-, no sorprende la interpretación de Rodríguez-Alcalá. Después del lenguaje renacentista y clasicista de los sonetos, la poesía de Roa Bastos se caracteriza por un cambio radical hacia la "imaginería onírica y alucinante", como García Lorca en sus romances nuevos (Rodríguez-Alcalá, 1955: 23). Además de una influencia particular del surrealismo en ambos escritores, se percibe otro paralelismo entre los dos: el uso de los símbolos y las metáforas que vinculan el mundo real e histórico con el universo atemporal de la magia.

\section{El bilingüismo español-guaraní}

Otra técnica recurrente en El trueno entre las hojas es el uso de diferentes lenguas al mismo tiempo y en este carácter bilingüe del libro se manifiesta también el compromiso político de Roa Bastos. El autor incluye 
muchas palabras y expresiones guaraníes en el texto español. Partyka, en su amplio estudio sobre el bilingüismo en Roa Bastos, aclara que en estos cuentos tempranos de El trueno entre las hojas se refleja "el carácter conflictivo de dos mundos que no solo se distinguen por la lengua, sino también por su organización temporal, espacial y conceptual" (Partyka, 1997b: 117, mi traducción). El bilingüismo de Roa Bastos es fundamental para entender su visión política en un país como Paraguay en el que el choque de culturas ha tenido un fuerte impacto a todos los niveles de la sociedad. En una entrevista elaborada por Jean L. Andreu, Roa Bastos aclara:

Este "guaraní-paraguayo" que ha perdido sus fuentes tradicionales, que no ha podido constituir una lengua escrita y tampoco una literatura, se halla sin embargo arraigado en la conciencia nacional del pueblo paraguayo, y se podría asegurar que en el plano de la comunicación masiva y en la expresión de un mundo mítico y emocional, mantiene aún su preeminencia sobre la lengua "culta". (Roa Bastos; Andreu, 1971: 211)

Se detiene entonces en el dilema que tiene cada autor paraguayo en el momento de elegir un idioma para su escritura. El autor busca una solución intermedia, "una combinación o integración semántica", pero lamenta que "[s]iempre quedará algo inexpresado." (Roa Bastos; Andreu, 1971: 211)

La manera en que el autor ha manejado este bilingüismo no siempre ha sido apreciada por los críticos. Rodríguez-Alcalá califica esta mezcla de español, guaraní y guaraní desvirtuado una "jerigonza" (RodríguezAlcalá, 1955: 33). Asimismo, para Trevisán la opción del español resulta "artificiosa" (Trevisán, 1967: 98). Todo depende de la perspectiva. Para un lector que no hable guaraní el texto es bien comprensible y el español justamente se enriquece gracias a este sustrato del guaraní. Además, el glosario guaraní-castellano, incluido al final del libro, ayuda mucho (251-253). Como bien explica Díaz Ruiz, se trata de una situación de diglosia:

El bilingüismo y la diglosia son unas de las claves más justas y reveladoras del oficio narrativo de este paraguayo. La diglosia, puntualiza el diccionario, es casi un sinónimo de bilingüismo pero con el matiz especial de que una de las lenguas goza de privilegios sociales o políticos superiores. [...] El encuentro o coexistencia de lenguas en Paraguay impone ampliar la caracterización y el uso de cada una de las lenguas, pues en el fondo de la elaboración artística de Augusto Roa Bastos se plantea este problema como un aspecto esencial. (Díaz Ruiz 1991: 38)

Cabe aclarar que el bilingüismo en Paraguay refleja una tensión entre la oralidad (el guaraní) y la escritura (el castellano). Si los surrealistas -sobre todo los dadaístas- han ido tan lejos hasta destruir su propio arte, implica que hay cierto desprecio por lo artificial, y así pues también por la escritura. De ahí que les fascine experimentar con imitaciones de la oralidad. ${ }^{10}$ Este conflicto puede ser interpretado desde dos perspectivas. Por un lado la escritura correspondería a la muerte, mientras que la oralidad coincidiría con la vida. Esta es también la percepción que nos ofrece Roa Bastos en la introducción de Las culturas condenadas: al transponer el discurso oral al escrito, la oralidad pierde su vigor (Roa Bastos, 1980: 16). Por otro lado, se puede considerar la escritura como el medio que garantice precisamente la conservación del discurso oral. Es el discurso por excelencia de la inmortalidad ya que los textos escritos sobreviven al autor. La escritura le hace entonces un favor a la oralidad, salvándola del olvido. El guaraní, a diferencia de otros idiomas indígenas en peligro de extinción, se mantiene muy vivo y fuerte: "En efecto, lo guaraní es, así lo demuestra la obra de Roa Bastos, un sustrato vivo, un elemento fecundo e interactuante que participa sustancial y vigorosamente en las expresiones sociales y culturales de su país” (Díaz Ruiz, 1991: 40).

\section{Conclusiones}

El análisis ha revelado una unidad interna que hace de El trueno entre las hojas una colección de cuentos integrados con características particulares que permiten ver la obra en su conjunto. Partimos de algunas analogías entre el pensamiento surrealista y esta colección de cuentos para luego analizar el compromiso

\footnotetext{
${ }^{10}$ Partyka analiza en detalle las técnicas orales y tradicionales en la narrativa de Roa Bastos, en particular las repeticiones de palabras: "Single word repetition is common in all narration, but is particularly noticeable in Roa's short stories where even the casual reader easily notes the powerful effects of redundancy within and between stories." (Partyka, 1997a: 94). Otras técnicas orales estudiadas por Partyka son por ejemplo las estructuras paralelas, las onomatopeyas o los sonidos de melodías.
} 
político del autor. Resultaron muy reveladores algunos conceptos psicoanalíticos de Jung como la inconsciencia colectiva, el sueño, el mito, el arquetipo, el héroe y el niño. También la comparación entre las obras de Roa Bastos y García Lorca llevó a resultados llamativos. Las obras del joven Lorca, como por ejemplo El Público, se caracterizan por la experimentación, el lenguaje vulgar, lo escandaloso y la argumentación ilógica, elementos que también se perciben en El trueno entre las hojas. Igualmente interesante ha sido la comparación a nivel de las imágenes y las metáforas, como bien se ve en la imagen de la luna.

Roa Bastos trabaja sobre todo desde su propia realidad paraguaya. Su compromiso político está en primer lugar con el pueblo de Paraguay, víctima de regímenes políticos duros. En los cuentos de El trueno entre las hojas surgen diferentes oposiciones: tradición y modernidad, mundo mitológico y mundo civilizado, español y guaraní... El libro es un reflejo de mundos y personajes en conflicto en un difícil proceso de búsqueda de identidad. En la combinación de crítica social y referencias al contexto paraguayo (el uso del guaraní) con algunos aspectos surrealistas en los años cincuenta quizá se podría entrever una especie de manifestación prototípica o precursora del naciente realismo mágico. Esta hipótesis podría constituir un punto de arranque interesante para futuros estudios sobre Roa Bastos. Del presente análisis podemos concluir que en El trueno entre las hojas Roa Bastos proporciona una visión universal del hombre a través de la mitología y la magia que tienen su origen en un pasado remoto de la humanidad y que se reactualizan de un modo misterioso en el pueblo paraguayo.

\section{Referencias bibliográficas}

Aldana, Adelfo (1975). La cuentística de Augusto Roa Bastos. Montevideo: Ediciones Géminis.

Aponte, Barbara B. (1982), "The Initiation Archetype in Arguedas, Roa Bastos and Ocampo", Latin American Literary Review 11(21), págs. 45-55.

Bareiro Saguier, Rubén (1976), “Trayectoria narrativa de Augusto Roa Bastos”, Texto Crítico 4 (mayo-agosto), págs. 36-46.

Berranger, Marie-Paule (1997). Panorama de la Littérature Française. Le surréalisme. Paris: Hachette.

Brescia, Pablo y Eduardo Romano (eds.) (2006). El ojo en el caleidoscopio, México: UNAM.

Buen Abad Domínguez, Fernando (2007), "El surrealismo en América Latina", Rebelión (23 de noviembre). Disponible en: http://www.rebelion.org/noticia.php?id=59446

Burgos, Fernando (1988). Las voces del Karaí: Estudios sobre Augusto Roa Bastos. Madrid: Edelsa.

Carbajal, Brent J. (1996). Historia ficticia y ficción histórica: Paraguay en la obra de Augusto Roa Bastos. Madrid: Editorial Pliegos.

Castellani, Riccardo (2012), "Surrealismo en el Paraguay”, Kipus. Revista Andina de Letras 31, semestre 1.

Díaz Ruiz, Ignacio (1991) “Roa Bastos: presencia indígena y conciencia nacional”, Plural, Excélsior, 31(241) (octubre), págs. 37-41.

Foster, David William (1969). The Myth of Paraguay in the Fiction of A. Roa Bastos. Chapel Hill: University of North Carolina Press.

García Lorca, Federico (1986). Romancero Gitano, Madrid: Alianza Editorial. (1987). El público. Madrid: Ediciones Cátedra.

Goic, Cedomil (1977), "El surrealismo y la literatura iberoamericana”, Revista Chilena de Literatura 8 (Abril), págs. 534.

Hesnard, Angelo (1984). La obra de Freud. México: Fondo de Cultura Económica.

Jung, Carl G. (1984). El hombre y sus símbolos. Barcelona: Caralt. BUC.

Lewi, Alain (1989). Le surréalisme. Paris: Pierre Bordas et fils.

Luscher, Robert M. (1989), “The short story sequence: An open book”, en S. Lohafer and J. E. Clarey (eds.). Short Story Theory at a Crossroads. Baton Rouge: Louisiana State University Press, págs. 148-167.

Mac Adam, Alfred (1991), "Octavio Paz, The Art of Poetry No. 42", The Paris Review 119. Disponible en: http://www.theparisreview.org/interviews/2192/octavio-paz-the-art-of-poetry-no-42-octavio-paz

Marcos, Juan Manuel (1983). Roa Bastos, precursor del post-boom. México: Editorial Katún S.A.

Montenegro, Patricia G. (2015), "Symbolism of the Shadows in Son of Man by Roa Bastos", Cultural and Religious Studies, July-Aug. 2015, vol. 3, no. 4, 185-200, doi: 10.17265/2328-2177/2015.04.002.

Nagel, James (2001). The Contemporary American Short Story Cycle. The Ethnic Resonance of Genre. Baton Rouge: Louisiana State University Press, págs. 1-17.

Orozco, Chema (2015), “Diez años sin Roa Bastos y sin pistas de sus obras desaparecidas”, Diario de León, 27 de abril. Disponible en:

https://www.diariodeleon.es/noticias/cultura/diez-anos-sin-roa-bastos-sin-pistas-sus-obrasdesaparecidas_974388.html 
Partyka, Betsy (1997a), "Traditional Oral Narrative Techniques in the Fiction of Augusto Roa Bastos (1953-1974)", Chasqui 26(1), págs. 93-101.

50(1), págs. 116-131.

Pecci, Antonio V. (s.f.), “Augusto Roa Bastos. Perfil biográfico 1917-2005”, Fundación Roa Bastos. Disponible en: http://fundacionroabastos.org/biografia.html

Piccini, Mabel (1973), “El trueno entre las hojas' y el humanismo revolucionario”, en Homenaje a Augusto Roa Bastos. Washington: Las Américas Publishing, págs. 237-249.

Rabassa, Gregory (1955), “Augusto Roa Bastos y 'El trueno entre las hojas””, Revista Hispánica Moderna 21(2), pág. 151.

Rispail, Jean-Luc (1991). Les surréalistes. Une génération entre le rêve et l'action. Paris: Gallimard.

Roa Bastos, Augusto (1977). El trueno entre las hojas. Barcelona: Editorial Bruguera.

(1979). Hijo de hombre. Barcelona: Argos Vergara.

-- (1980). Las culturas condenadas. México: Siglo XXI, América Nuestra.

Roa Bastos, Augusto y Jean L. Andreu (1971), "Entretien avec Augusto Roa Bastos" Cahiers du monde hispanique et luso-brésilien, $\mathrm{n}^{\mathrm{o}}$. 17, págs. 207-218, doi: https://doi.org/10.3406/carav.1971.1835

Rodríguez-Alcalá, Hugo (1955), “Augusto Roa Bastos y 'El trueno entre las hojas””, Revista Iberoamericana 20(39), págs. 19-45.

Tovar Blanco, Paco (2002), "Ecos lorquianos en la memoria poética del Paraguay: Josefina Pla, Augusto Roa Bastos y Hérib Campos Cervera”, América sin nombre 4 (dic.), págs. 91-101.

Trevisan, Lili Olga (1967), “Literatura de una tierra Joyosa”, Revista de Literaturas Modernas 6, págs. 79-107.

Vila Barnés, Gladys (1984). Significado y coherencia del universo narrativo de Augusto Roa Bastos. Madrid: Editorial Orígenes. 